\title{
Two brothers with heart defects and limb shortening: case reports and review
}

\author{
W Reardon, J Hurst, T I Farag, C Hall, M Baraitser
}

\begin{abstract}
Two male Arab sibs are reported with congenital heart disease and skeletal malformations. Other published case reports sharing some features in common with these brothers are considered. However, clinical and radiological features in these boys are distinct enough to represent a new cardioskeletal syndrome.
\end{abstract}

Cardioskeletal malformations may occur together in a number of recognisable syndromes. The best known of these are cardiac defects in association with proportional short stature in Noonan syndrome, and upper limb malformations occurring with congenital heart defects in the Holt-Oram syndrome. Few other recognisable syndromes combine a congenital heart defect with limb shortening. This report describes two brothers, offspring of consanguineous parents, in whom the predominant clinical features are abnormalities of the heart and skeleton. The combination of the anomalies observed has not been seen in a previously recognised syndrome.

\section{Case reports}

The pedigree is shown in fig 1 . The parents were healthy, Kuwaiti first cousins (III-1 and III 2 ). The

Mothercare Department of Paediatric Genetics, Institute of Child Health, 30 Guilford Street, London WCIN $1 E H$. W Reardon

Clinical Genetics Unit, Hospital for Sick Children, Great Ormond Street, London WC1N 3JH.

J Hurst, M Baraitser

Kuwait Medical Genetics Centre, PO Box 31145, Sulibikhat 90802, Kuwait.

T I Farag

Department of Radiology, Hospital for Sick Children, Great Ormond Street, London WCIN 3JH.

C Hall

Correspondence to Dr Reardon.

Received for publication 20 February 1990.

Revised version accepted for publication 4 June 1990.

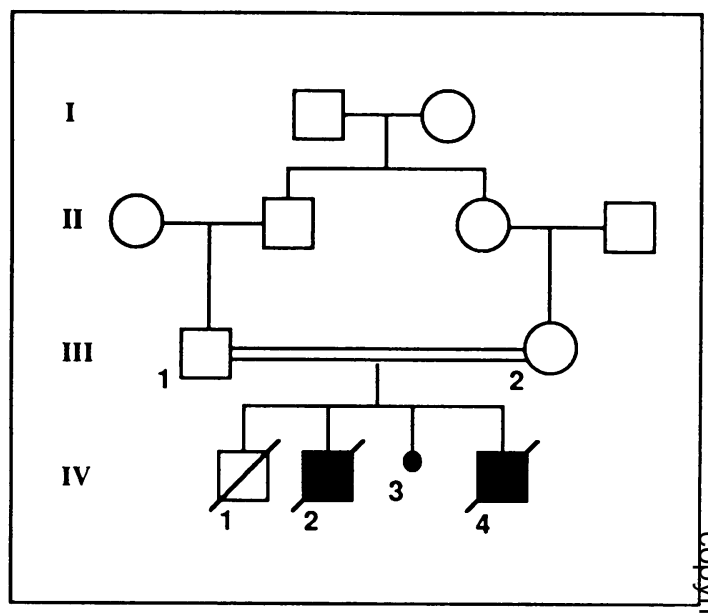

Figure 1 Family pedigree. The probands are $I V \cdot 2$ and $I V \cdot 4$.

first pregnancy resulted in a late intrauterine death and a stillborn male infant was delivered. Congenital malformation was not noted in this infant and necropsy was not performed.

Case IV· 2 was born at 39 weeks' gestation by spontaneous vaginal delivery. Owing to maternal anxiety regarding paucity of fetal movements, an ultrasound scan was performed at 26 weeks' gestation. Biparietal diameter was appropriate to gestational age but significant shortening of the femora and humeri was detected. Furthermore, the vertebrae were felt to be short and broad. A fetal bradycardia was noted, but heart rhythm was regular.

Birth weight was $3100 \mathrm{~g}$ (25th centile), head circumference $34 \mathrm{~cm}$ (25th to 50th centile), and length $42 \mathrm{~cm}(<3 \mathrm{rd}$ centile). The chest was thought to be narrow and all limbs were noted to be short. In view of continuing central cyanosis, a cardiac echogram was performed which showed gross hypoplasia of the right ventricle and tricuspid valve, with a large atrial septal defect, pulmonary atresia, and a cleft mitral valve. The infant died on the second day of life.

The third pregnancy ended in a first trimester spontaneous abortion.

Case IV 4 was born at term. Ultrasound scans at 13 


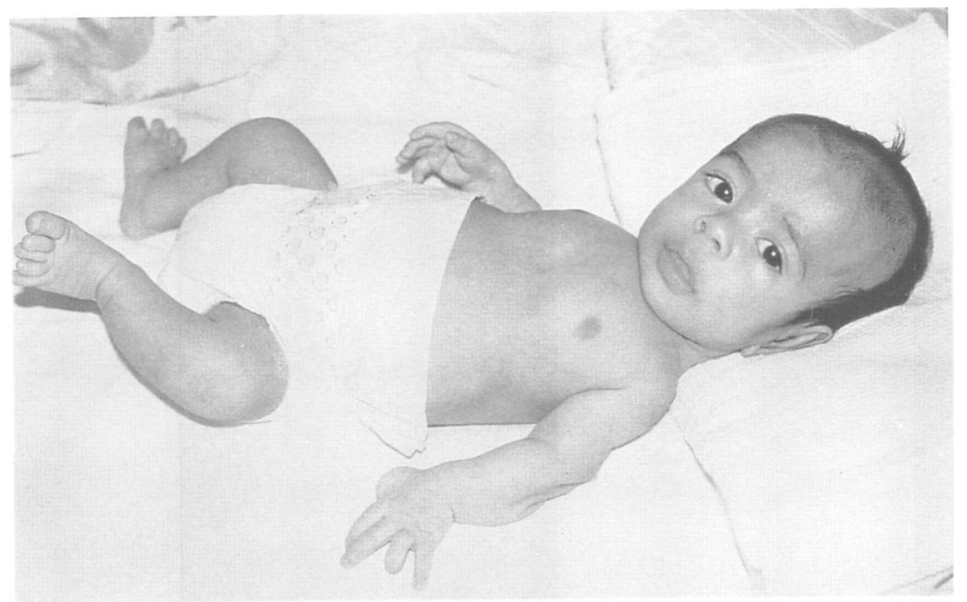

Figure 2 Patient IV 4 . Note the limb shortening.

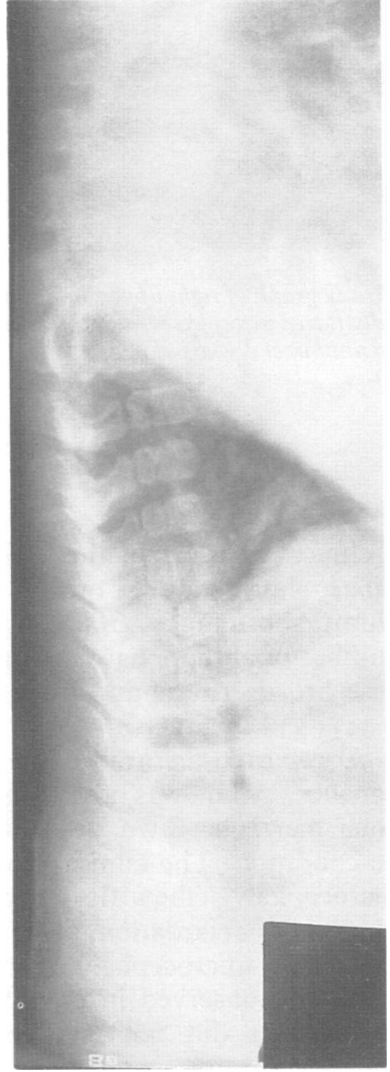

Figure 3 Lateral spine radiograph with coronal clefts throughout the dorsal spine.

and 22 weeks' gestation detected no abnormality but when repeated at 30 weeks shortening of all limbs was detected. Birth weight was $3000 \mathrm{~g}$ (25th centile). Limb shortening was evident (fig 2). When reviewed

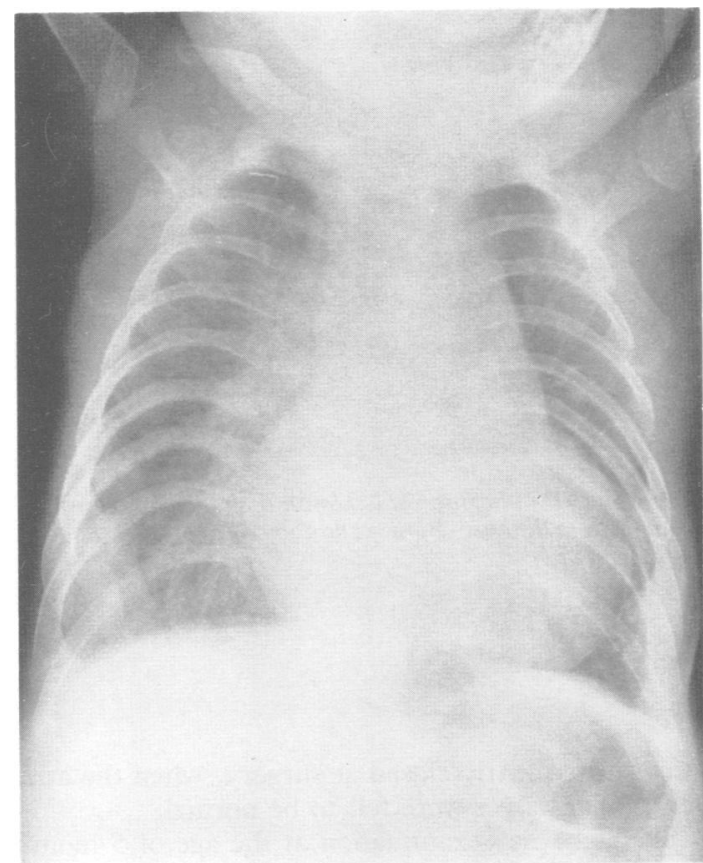

Figure $4 A P$ chest radiograph showing narrow thorax with large anterior ends of 6 th to 8 th ribs, and marked cardiac enlargement with pulmonary plethora.

at 3 months of age a heart murmur and clinical evidence of cardiac failure were noted and he was referred for investigation. On admission, weight was on the 10th centile, head circumference on the 10th centile, and length well below the 3 rd centile. Clinical examination showed a narrow chest. Cardiac investigations showed a ventricular septal defect and an atrial septal defect (secundum type). These defects 


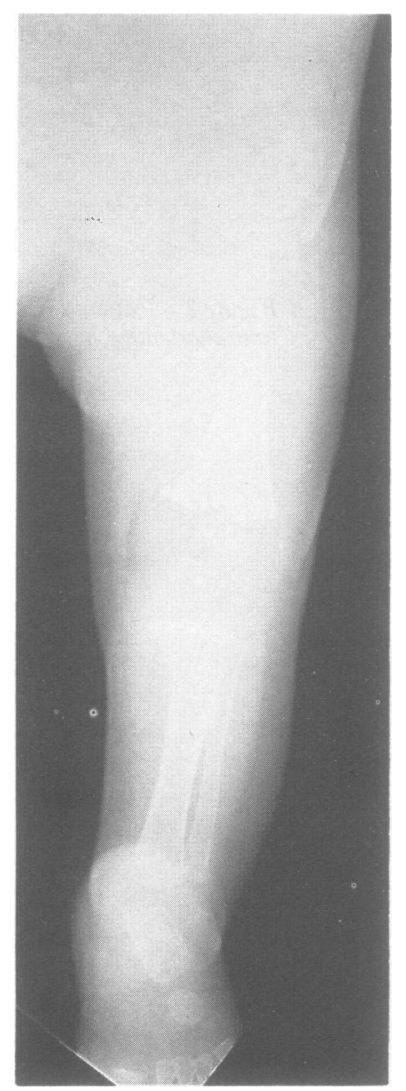

Figure 5 AP radiograph of left lower limb showing flared metaphyses at the knee. Bone maturation corresponds to about 35 weeks' gestation.

were subsequently closed at surgery, when the atrioventricular valves were felt to be normal.

Skeletal $x$ ray examination at the age of 5 months showed mild thoracolumbar kyphosis and coronal clefts extending through the dorsal and lumbar vertebrae (fig 3 ). Chest $x$ ray confirmed the clinical impression of a narrow thorax and showed prominence of the anterior ends of the sixth, seventh, and eighth ribs as well as cardiac enlargement with pulmonary plethora (fig 4). The long bones were shortened with metaphyseal flaring (figs 5 and 6 ).

The femoral necks were broad, with prominent lesser trochanters (fig 7). Bone maturation was retarded at the knee but advanced at the wrist with three carpal centres ossified. Chromosomes were normal as were parental chromosomes, performed with $\mathrm{G}$ banding techniques. This infant has since died of cardiac complications.

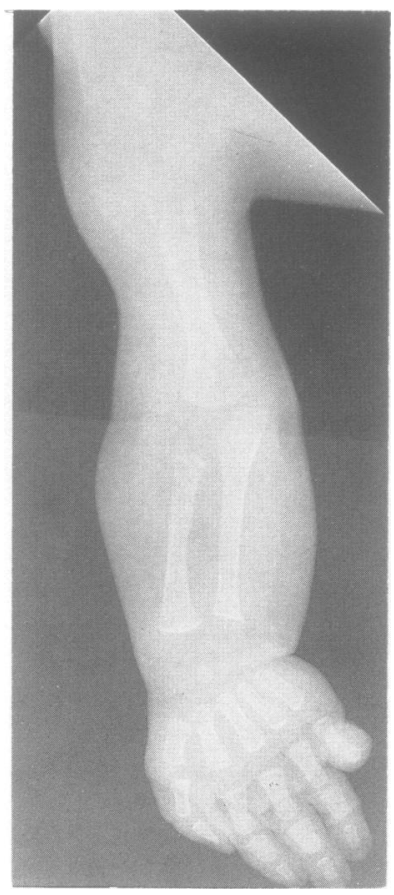

Figure 6 AP radiograph of right upper limb showing short lon bones with mildly flared metaphyses, and three carpal centres, usually not seen until over 2 years of age.

\section{Discussion}

The critical clinical features in these brothers were disproportionate short stature, owing to a mainly rhizomelic limb shortening, and congenital heart disease. A number of authors have documented cases which fit these broad criteria and these will now be considered.

Urbach et al ${ }^{1}$ reported an Arab baby with cardioskeletal anomalies, who was the offspring of a consanguineous marriage. Two dead sibs probably had the same condition. The clinical features in this case were microcephaly, elbow flexion contractures, severe psychomotor retardation, and pulmonary stenosis. By contrast, microcephaly, contractures, or retardation were not observed in our cases and the cardiac malformations did not include pulmonary stenosis (see table 1 for comparison of clinical features). Radiological features in the case of Urbach et $a l^{1}$ were a very distinctive upper limb rhizomelia and flared epiphyses, platyspondyly, and bifid distal phalanx of the thumb. The femora were of normal length. As seen in table 2, these radiological features differ substantially from those noted in the subject of this report.

Barrow and Fitzsimmons ${ }^{2}$ described a male child 


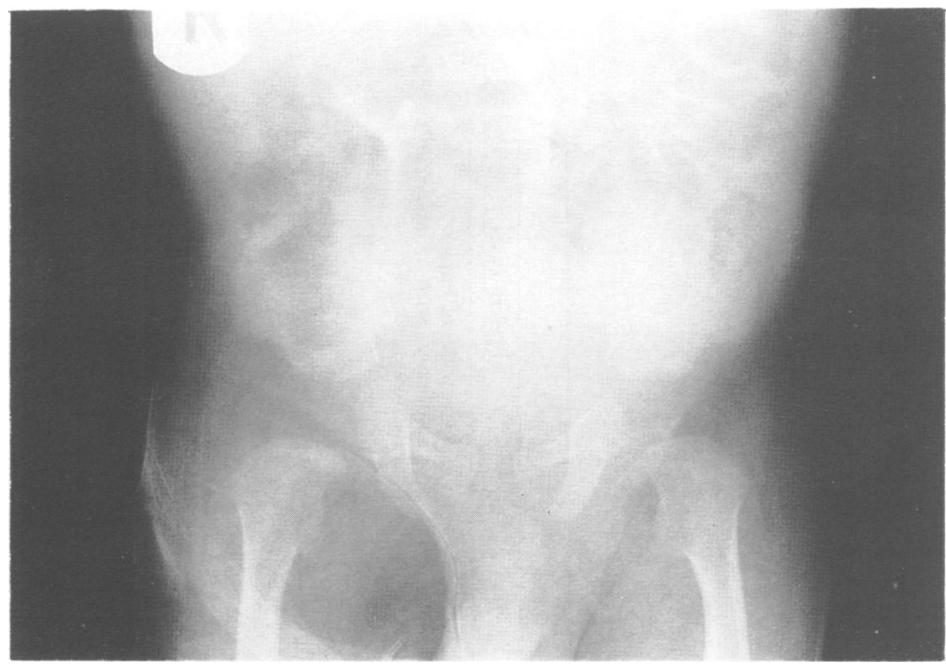

Figure 7 AP radiograph of pelvis showing flared iliac wings, broad femoral necks, and prominent lesser trochanters.

with severe cyanotic congenital heart disease owing to a single ventricle and truncus arteriosus. Rhizomelic short stature, particularly of the upper limbs, was also observed in this child. Unlike the cases we describe, marked facial dysmorphism was present in this child, with a very prominent nasal bridge and sloping forehead. The nature of the cardiac lesion was also substantially different from the cases we describe (table 1).

Sedaghatian $^{5}$ described three Iranian sibs with rhizomelic limb shortening and platyspondyly. A further sib pair, also of Iranian extraction, was subsequently reported by Opitz et al. ${ }^{3}$ These children all died early in neonatal life of severe respiratory and metabolic abnormalities comprising severe respiratory acidosis, hypocalcaemia, and raised alkaline phosphatase levels, probably of renal origin. Necropsy showed no evidence of a cardiac lesion (table 1). While case IV'2 of the current report died in the neonatal period, this was almost certainly because of cardiac complications. With regard to radiological features, Sedaghatian syndrome also differs from the present report in that, although rhizomelia is common to both conditions, Sedaghatian syndrome patients have very irregular metaphyseal splaying at the knees and ankles not observed in the condition we describe. Furthermore, unlike our patients, coronal clefting was not seen in Sedaghatian syndrome patients (table 2).

Although Verloove et $a t^{6}$ described a condition with rhizomelia and congenital heart disease, that condition also involved cleft lip, bilobular lungs, and oligopolysyndactyly, features not observed in the condition we describe.

The report which approximates most closely to the cases we describe is that of Kozlowski et al. ${ }^{4}$ Two half sibs were reported. Unlike our cases, both children had talipes equinovarus. Cardiac anomalies consisted of thickening of the left atrium, mitral, and tricuspid valves in case $I$ and tricuspid incompetence and pulmonary hypertension in case II. Intracardiac shunts were excluded in both these cases whereas intracardiac shunts were cardinal clinical features of both cases in the present report (table 1).

Radiologically too, our cases differ from those of Kozlowski et al. ${ }^{4}$ Although coronal clefting of the vertebral bodies and limb shortening are features common to both reports, some essential differences are also observed. The patients in the report of Kozlowski et al had bifid distal humeral ends and radial subluxation at the elbow joint. Some metaphyseal flaring of the humeri and femora was seen in our patients (figs 4 and 5), but the bifid distal humeral ends, so characteristic of the Kozlowski report, were absent and the radii in our patient were not dislocated (table 2).

The clinical features in the sibs we describe were mainly rhizomelic limb shortening and congenital heart disease. These features, combined with radiological signs of coronal clefting of the vertebrae with shortening and metaphyseal flaring of the limbs, have not been previously described. Although radiological data on case IV·2 are unavailable, the clinical similarities between these brothers are compelling. That they shared the same condition is further supported by the ultrasonic diagnosis of short limbs made in both cases early in the third trimester. In view of the parental consanguinity, it seems likely that this report represents a new autosomal recessive condition. It is difficult to evaluate parental consan- 


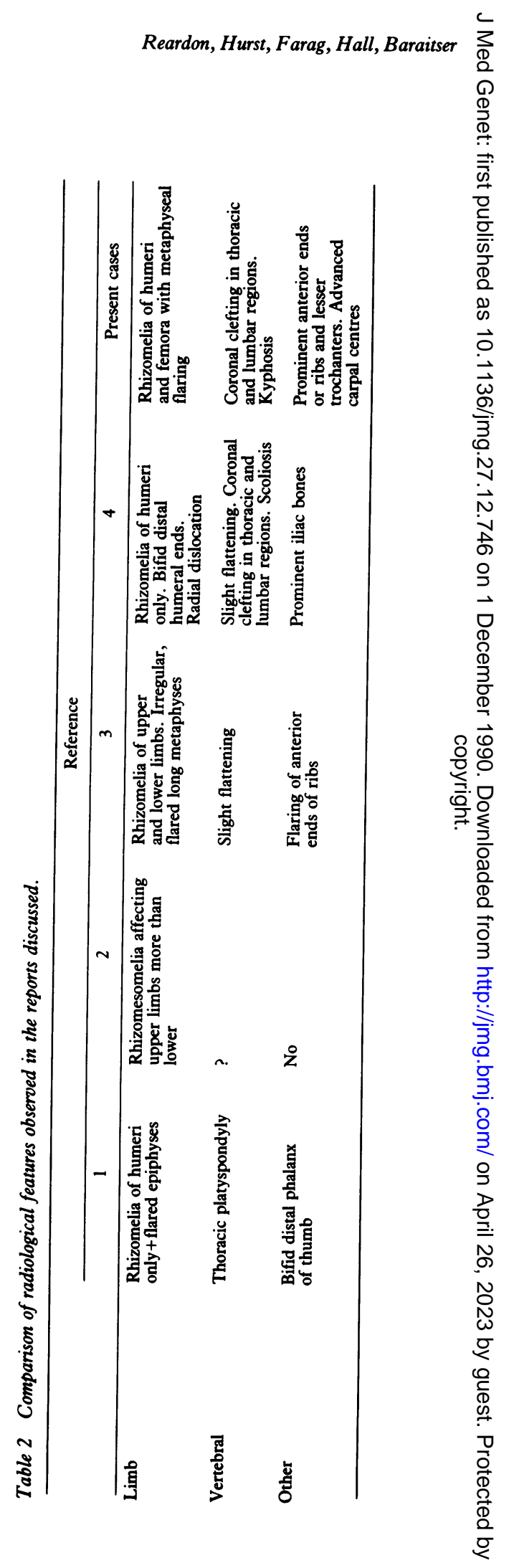


guinity in this case as the inbreeding coefficient in the Middle East is high. ${ }^{7}$ However, the occurrence of a rare syndrome in two brothers suggests that this is a genetically determined condition, the mechanism of inheritance awaiting further reports.

We would like to thank Miss Jo Bramfitt for her help in typing the manuscript.

1 Urbach D, Hertz M, Shine M, Goodman RM. A new skeletal dysplasia syndrome with rhizomelia of the humeri and other malformations. Clin Genet 1986;29:83-7.
2 Barrow M, Fitzsimmons JS. A new syndrome-short limbs, abnormal facial appearance and congenital heart defect. $A m \mathcal{F}$ Med Genet 1984;18:431-3.

3 Opitz JM, Spranger JW, Stoss HR, Pesch HJ, Azadeh B. Brief clinical report: Sedaghatian congenital lethal metaphyseal chondrodysplasia observations in a second Iranian family and histopathological studies. Am $\mathcal{F}$ Med Genet 1987;26:583-90.

4 Kozlowski KS, Celermajer JM, Tink AR. Humero spinal dystosis with congenital heart disease. Am $\mathcal{F}$ Dis Child 1974;127:407-10.

5 Sedaghatian MR. Congenital lethal metaphyseal chondrodysplasia: a newly recognised complex autosomal recessive disorder. $\mathrm{Am} \mathrm{f}$ Med Genet 1980;6:269-74.

6 Verloove SP, Brubakk AM, Ruys JH. Extensive congenital malformations in 2 siblings. Maternal pre-diabetes or a new syndrome? Acta Paediatr Scand 1931;70:767-9.

7 Al-Awadi SA, Moussa MA, Naguib KK, et al. Consanguinity among the Kuwaiti population. Clin Genet 1985;27:483-6. 